\title{
Angiopoietin-1 reduces vascular endothelial growth factor-induced brain endothelial permeability via upregulation of $\mathrm{ZO}-2$
}

\author{
SAE-WON LEE ${ }^{1}$, WOO JEAN KIM ${ }^{3}$, HYOUNG-OH JUN ${ }^{2}$, \\ YOON KYUNG CHOI ${ }^{2}$ and KYU-WON KIM ${ }^{2}$ \\ ${ }^{1}$ Clinical Research Institute, Seoul National University Hospital, Seoul 110-744; ${ }^{2}$ Division of Pharmaceutical Bioscience, \\ College of Pharmacy and Research Institute of Pharmaceutical Sciences, Seoul National University, \\ Seoul 151-742; ${ }^{3}$ Department of Urology and Laboratory of Regenerative Sexual Medicine, \\ Inha University School of Medicine, Incheon 400-711, Korea
}

Received October 14, 2008; Accepted December 1, 2008

DOI: 10.3892/ijmm_00000128

\begin{abstract}
Brain microvessels possess barrier structures comprising tight junctions which are critical for the maintenance of central nervous system homeostasis. Brain vascular diseases, such as ischemic stroke damage to blood-brain barrier, increase the vascular permeability, and then lead to vasogenic brain edema. Herein, we examined whether angiopoietin-1 (Ang-1) could regulate zonula occludens-2 (ZO-2) expression and counteract vascular endothelial growth factor (VEGF)-induced vascular permeability. When we treated brain microvascular endothelial cells with Ang-1, Ang-1 caused a time- and dosedependent increase of ZO-2 and down-regulation in endothelial permeability. VEGF, one of the key regulators of ischemiainduced vascular permeability, increased endothelial cell permeability in vitro, whereas, Ang-1 reversed this VEGF effect by up-regulating ZO-2 expression. Additionally, the recovery effect of Ang-1 on permeability was strongly blocked by siRNA against ZO-2. Collectively, our results suggest that Ang-1 shows anti-permeability activity through up-regulation of $\mathrm{ZO}-2$
\end{abstract}

\section{Introduction}

Brain barriers protect the central nervous system (CNS) from harmful components of peripheral circulation (1). In vertebrates, the blood-brain barrier exists at the level of the endothelial cells that form brain capillaries (2), and the presence of tight intercellular junctions between endothelial cells support

Correspondence to: Dr Sae-Won Lee, Clinical Research Institute, Seoul National University Hospital, Seoul 110-744, Korea E-mail: sawolee@snu.ac.kr

Key words: endothelial barrier, tight junction, ischemia-reperfusion injury, brain edema, blood-brain barrier barrier function with low permeability and high electrical resistance (3-5). Tight junctions are composed of many junctional proteins including occludins, claudins, junctional adhesion molecules (JAMs), which are associated with at least one of the zonula occludens proteins (ZOPs) (6). ZOPs, in turn, establish a link between the junction site and the cytoskeleton by interacting directly with actin filaments $(7,8)$. The observation that ZOPs not only associate with each other but also with components of adherens and gap junctions in cells lacking tight junction structure (9) suggests a universal and important role for ZOPs at cytoplasmic surfaces.

Mammalian ZOPs comprise of zonula occludens (ZO)-1, -2 , and -3 (5). ZO-1 was the first protein associated with tight junctions of endothelial cells and well characterized tight junction protein (10). Tight junction associated protein $\mathrm{ZO}-2$ interacts with ZO-1 and binds directly to the $\mathrm{COOH}$-terminal cytoplasmic tail of the transmembrane protein occludin (11).

Pathological conditions, including ischemia, tumors and inflammation, are accompanied by a breakdown of the brain barrier, increase in permeability of the brain microvasculature and conduct the development of vasogenic brain edema (12). Vascular endothelial growth factor (VEGF), known as vascular permeability factor, is a possible candidate for the development of ischemia- and tumor-induced vasogenic brain edema $(13,14)$. During development, VEGF and Ang-1 collaborate to regulate vascular formation (15). Although VEGF initiates proliferation and migration of endothelial cells and can promote the formation of new vessels (15), Ang-1 is required for the stabilization of endothelial contacts with surrounding mural cells to form mature vessels (16). Ang-1, a strong blood-vesselanti-permeability factor, binds to the endothelial Tie2 receptor tyrosine kinase (17).

Several studies demonstrated that Ang-1 is involved in the reduction of VEGF-induced vascular permeability. In vivo mouse ischemia model, coapplication of Ang-1 and VEGF showed a reduction of the ischemic- and edema-volumes in comparison with VEGF-treated mice (18). ZO-1 immunostaining was more complete on the microvessel in the Ang-1 plus VEGF protein treated group compared with VEGF protein 
group in mouse brain (19). We previously reported indirect evidence that Ang-1 might stimulate the formation of bloodbrain barrier and likely regulate the expression of several tight junction proteins including ZO-1, -2 and occludin (20). In addition, Ang-1 up-regulates ZO-1 in retina endothelial cells (21). Here, we show that Ang-1 could counteract VEGFinduced vascular permeability by regulating ZO-2 in brain endothelial cells.

\section{Materials and methods}

Cell line, recombinant proteins and antibodies. Primary human brain microvascular endothelial cells (HBMECs) were purchased from the Applied Cell Biology Research Institute and grown on $0.3 \%$ gelatin-coated dishes in complete serum-free medium (Cell Systems) or in M199 supplemented with $20 \%$ FBS (Invitrogen), $3 \mathrm{ng} / \mathrm{ml}$ basicFGF (Millipore), $5 \mathrm{U} / \mathrm{ml}$ heparin (Sigma) and $1 \%$ penicillin/streptomycin. Recombinant human $\mathrm{VEGF}_{165}$ (rVEGF) and angiopoietin-1 (rAng-1) were purchased from R\&D Systems. ZO-2 was from Santa Cruz. Phopho-AKT and AKT antibodies were from Cell Signaling. Anti- $\beta$-actin antibody was from Sigma. Horseradish peroxidase-conjugated antibodies against mouse and rabbit immunoglobulins were purchased from Dako.

Rhodamine B isothiocyanate-dextran permeability assay. Permeability across the HBMECs cultured on type I collagencoated transwell units $(6.5-\mathrm{mm}$ diameter, $3.0-\mu \mathrm{m}$ pore size polycarbonate filter; Corning) was measured as described previously (20). After HBMECs became confluent, Human Endothelial-SFM media (Invitrogen) was treated for $15 \mathrm{~h}$, followed by rVEGF $(50 \mathrm{ng} / \mathrm{ml})$ and rAng1 $(50-100 \mathrm{ng} / \mathrm{ml})$ treatment for indicated time (h). Permeability was measured by adding $0.1 \mathrm{mg}$ of Rhodamine $\mathrm{B}$ isothiocyanate (RITC)labeled dextran (molecular weight, $\sim 10,000$ )/ml to upper chamber. After incubation for $10 \mathrm{~min}, 50 \mu \mathrm{l}$ of sample from the lower compartment was diluted with $50 \mu 1$ of phosphatebuffered saline and measured for fluorescence at $635 \mathrm{~nm}$ when excited at $540 \mathrm{~nm}$ with a spectrophotometer (Tecan Spectra Fluor).

SDS-PAGE and immunoblotting. Proteins were extracted with lysis buffer (40 mM Tris pH 7.4, $10 \mathrm{mM}$ EDTA, $120 \mathrm{mM}$ $\mathrm{NaCl}, 0.1 \%$ NP-40, protease inhibitor cocktail (Roche Applied Science) and protein concentration was measured by Bradford assay. Total protein (20 $\mu \mathrm{g} / \mathrm{lane})$ were loaded, separated by SDS-PAGE and transferred onto Hybond ECL nitrocellulose membrane (Amersham Biosciences). The membranes were incubated for $1 \mathrm{~h}$ with blocking solution $(5 \%$ skim milk in $0.1 \%$ Tween-20 PBS) and then incubated overnight at $4^{\circ} \mathrm{C}$ with appropriate antibody. Membrane was washed with $0.1 \%$ Tween-20 PBS and then incubated for $1 \mathrm{~h}$ with secondary antibody. The membrane was washed with $0.1 \%$ Tween-20 PBS and the signals were developed using ECL plus detection system (Amersham Bioscience). For internal loading control, anti-ß-actin antibody was used.

RNA interference and RT-PCR. HBMECs were grown to $80 \%$ confluence, and small interfering RNAs (siRNAs) $(50 \mu \mathrm{M})$ against ZO-2 were transfected into the cells using
MetafectenePro (Biontex). siRNA transfection was performed according to the manufacturer's instructions. ZO-2 siRNA and the control nonsilencing siRNA were purchased from Santa Cruz. Total RNA was isolated using TriZol reagent (Invitrogen). RT-PCR was performed according to manufacturer's instructions (Promega). The following sets of primers were used: human ZO-2, 5'-CTTATTCGGCCCCATA GCTG-3' (forward); 5'-CCATGGCGGTTAAGTAGGAC-3' (reverse); GAPDH, 5'-CCTCTGGAAAGCTGTGGCGT-3' (forward); 5'-TTGGAGGCCATGTAGGCCAT-3' (reverse). The PCR products were separated on $1.2 \%$ agarose gels and visualized using ethidium bromide staining under UV transillumination.

Data analysis and statistics. Quantification of band intensity was analyzed using TINA 2.0 (RayTest) and normalized to the intensity of $B$-actin band. All data are presented as mean \pm SD. Statistical significance was evaluated with pairedstudent t-test for comparison between 2 groups. A probability value of $<0.005$ was considered significant.

\section{Results}

rAng-1 treatment upregulates the expression of $\mathrm{ZO}-2$ and reduces permeability in HBMECs. We first tested the possibility that rAng-1 might regulate the expression of ZO-2 in brain endothelial cells. To evaluate whether rAng-1 activated the angiopoietin signaling pathway in HBMECs, we checked the AKT pathway activation in response to $\mathrm{rAng}-1$ treatment (Fig. 1A and B). The phosphorylated Akt is strongly induced by treatment of rAng-1. This pAKT induction indicated that HBMECs strongly responded to rAng-1. Interestingly, the expression of ZO-2 was time-dependently increased after treatment of rAng-1 (Fig. 1A). Also, ZO-2 mRNA and protein showed a dose-dependent up-regulation (Fig. 1B). Using the passage of RITC-dextran through monolayers of HBMECs as a measure of permeability, we found a parallel result that rAng-1 significantly reduced vascular permeability in a dose response $(\mathrm{p}<0.005)$ (Fig. 1C).

ZO-2 reduction by $r V E G F$ is recovered by combination treatment of rAng-1 and $r V E G F$. VEGF is a likely candidate for the development of ischemia- and tumor-induced vasogenic brain edema (13). To examine whether rVEGF affects the ZO-2 protein level, we exposed HBMECs to $\mathrm{rVEGF}(50 \mathrm{ng} / \mathrm{ml})$ for $3 \mathrm{~h}$ (Fig. 2A). ZO-2 expression was markedly decreased by rVEGF. However, when rAng-1 (100 ng/ml) was treated together with rVEGF to HBMECs, the decrease of ZO-2 expression strongly recovered (Fig. 2A). We confirmed this result using RITC-dextran permeability assay (Fig. 2B). Vascular permeability significantly increased by rVEGF $(\mathrm{p}=0.001)$, yet, it was markedly attenuated by adding rAng-1 into rVEGF treated HBMECs ( $\mathrm{p}=0.001$ ) (Fig. 2B). Thus, these results suggest that $\mathrm{rAng}-1$ may recover vessel tightness in part through ZO-2.

Anti-permeability effect of rAng- 1 was blocked by siRNA against ZO-2. To conform the mechanism of rAng-1 in antipermeability effect, we transfected the siRNA targeting ZO-2 (sizO-2) into the HBMECs. As shown in Fig. 3A, we were 
(A)
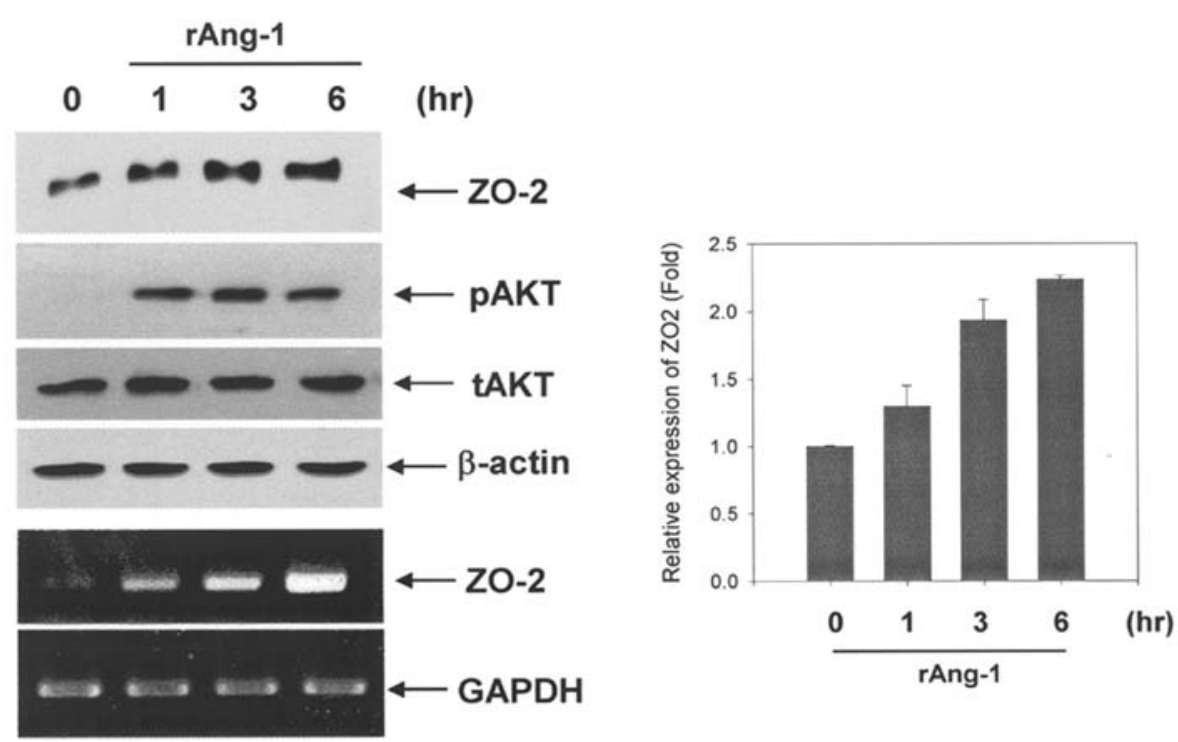

(B)
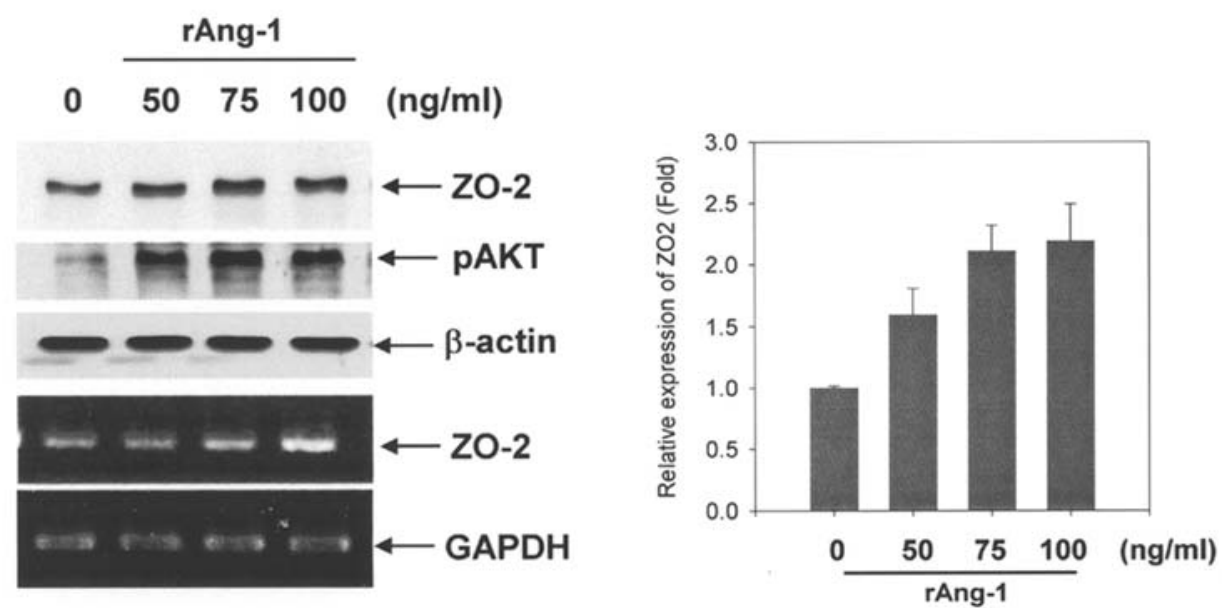

(C)

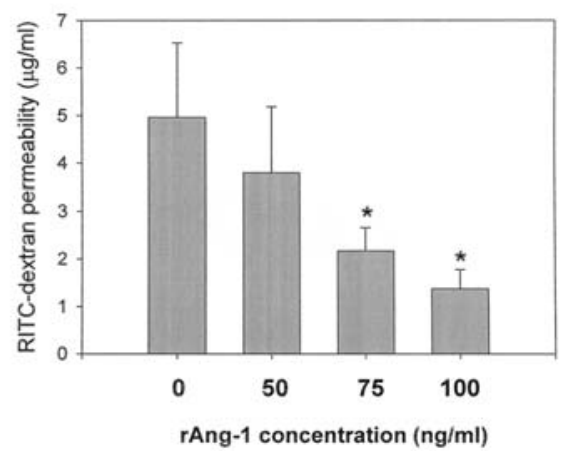

Figure 1. rAng-1 regulates the expression of ZO-2, tight junction protein, in HBMECs. (A) rAng-1 $(100 \mathrm{ng} / \mathrm{ml})$ time-dependently increased the ZO-2 expression. (B) Dose-dependent up-regulation of ZO-2. HBMECs were incubated for $3 \mathrm{~h}$ with indicated concentration of rAng-1. The quantification of the ZO-2 immunoblot from two independent experiments is shown on the right. $B$-actin and GAPDH served as the controls for same protein and RNA levels (A and B). (C) RITC-dextran permeability of HBMECs seeded on Transwell filter. HBMECs were incubated in Human Endothelial-SFM media for $15 \mathrm{~h}$, followed by rAng- 1 treatment with indicated concentration for 3 h. ${ }^{*} p<0.005$ compared with HBMECs with media alone. Three experiments were done independently.

able to detect the complete inhibition of ZO-2 expression in mRNA and protein levels after ZO-2 siRNA $(50 \mu \mathrm{M})$ transfection. Control siRNA (siCon) transfection had no effect on ZO-2 expression (Fig. 3A). In the permeability assay, rVEGF significantly increased the endothelial permeability $(\mathrm{p}<0.005)$, whereas rAng-1 plus rVEGF group strongly reduced permeability compared with rVEGF treated group $(\mathrm{p}<0.005)$ (Fig. 3B). Parallel to Fig. 3A, control siRNA did not alter endothelial permeability compared with rAng-1 plus rVEGF treatment group. However, the recovery effect for endothelial permeability by rAng-1 was completely blocked

by ZO-2 siRNA transfection ( $\mathrm{p}=0.001$ ) (Fig. 3B), suggesting that anti-permeability effect of Ang-1 in the presence of VEGF may occur via at least the regulation of ZO-2.

\section{Discussion}

Tight junctions in brain vessels have a function that reduces the permeability and builds up the CNS barrier, which restricts the free molecular exchange between blood and CNS tissue. This restriction protects CNS from harmful components of the blood and allows the uptake of essential molecules (3). Intact tight junctions between brain capillary endothelial cells are critical for normal brain barrier function. Alterations in 


\section{(A)}
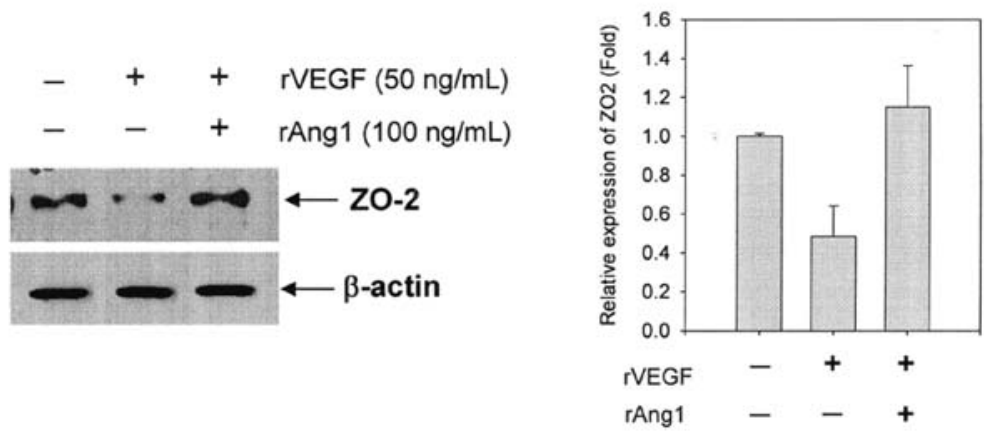

(B)

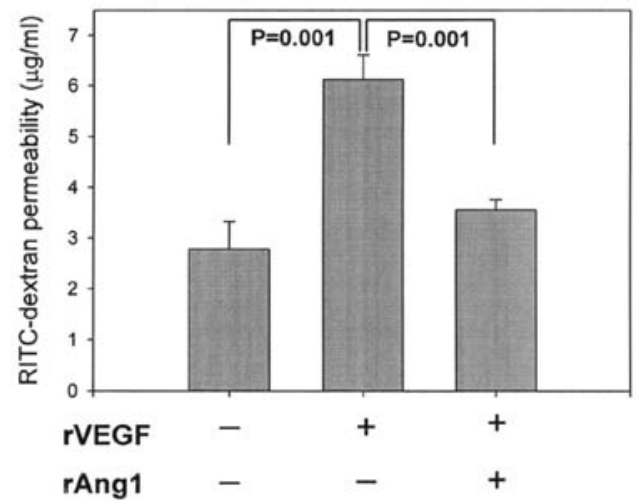

Figure 2. rAng-1 recovered rVEGF-induced ZO-2 reduction. (A) Expression of ZO-2 in HBMECs treated with $50 \mathrm{ng} / \mathrm{ml} \mathrm{rVEGF}$ and $100 \mathrm{ng} / \mathrm{ml} \mathrm{rAng-1} \mathrm{for} 3 \mathrm{~h}$ was analyzed by Western blot $(\mathrm{n}=4)$. The quantification of the $\mathrm{ZO}-2$ immunoblot from four independent experiments is shown on the right. (B) RITC-dextran passage was analyzed for vascular permeability in HBMECs under the same conditions as in A. Three experiments were independently performed.

(A)

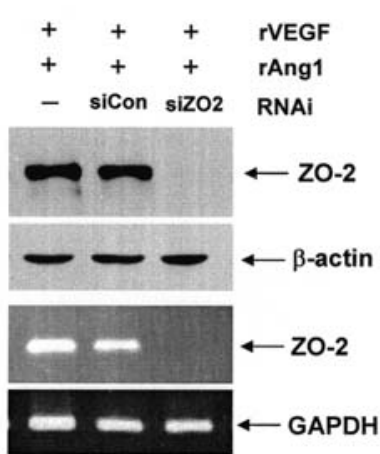

(B)

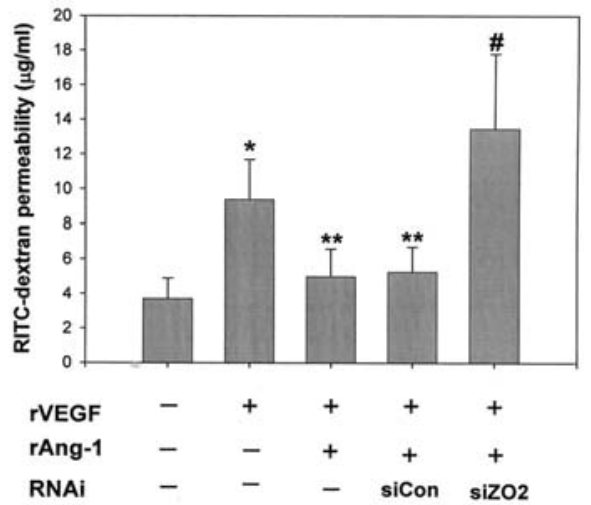

the composition and the distribution of tight junction proteins would result in increased blood-brain barrier permeability.

Notably, several reports suggest that the regulation of expression of tight junction proteins is important in barrier function as well. Reduction of ZO-2, a membrane-associated tight junction protein, was regarded as the cause of human immunodeficiency virus (HIV) entry into the CNS by disruption of the blood-brain barrier (22). Tat protein of HIV decreased ZO-2 expression, whereas total levels of occludin and ZO-1 remained unchanged in brain microvascular endothelial cells (22). Brain edema occurred in fulminant hepatic failure mice. ZO-2 expression was reduced and its distribution was altered in the tight junctions. These effects further preceded the increased blood-brain barrier permeability thus it may cause

Figure 3. siRNA against ZO-2 abolished the anti-permeability effect of rAng-1 on rVEGF treated HBMECs. (A) HBMECs were transfected with siRNA targeting ZO-2 (siZO-2) and control nonsilencing siRNA (siCon), incubated for $24 \mathrm{~h}$, then treated with $50 \mathrm{ng} / \mathrm{ml} \mathrm{rVEGF}$ and $100 \mathrm{ng} / \mathrm{ml} \mathrm{rAng-1}$ for $3 \mathrm{~h}$. ZO-2 protein and mRNA were analyzed $(\mathrm{n}=3)$. (B) RITC-dextran passage was analyzed for endothelial permeability in HBMECs under the same conditions as in A. Independent experiments were repeated two times. ${ }^{*} \mathrm{p}<0.005$ compared with HBMECs with media only; ${ }^{* *} \mathrm{p}<0.005$ compared with rVEGF treated HBMECs; ${ }^{p} \mathrm{p}=0.001$ compared with rVEGF plus rAng- 1 treated- or siCon transfected-HBMECs. 
brain edema in fulminant hepatic failure (23). These reports support the importance of ZO-2 in functional blood-brain barrier structure.

Brain tumors, ischemic stroke and trauma are involved with barrier disruption, leading to the development of vasogenic brain edema (24). Hypoxia-induced VEGF is known as a key regulator of these permeability changes (25). VEGF is an angiogenic growth factor whose expression correlates with brain angiogenesis (15). Treatment of VEGF, initially named vascular permeability factor, increased microvascular permeability and decreased occludin and ZO-1 levels (26-28). In our experiment, we found that rVEGF treatment to HBMECs strongly decreased the expression of ZO-2 (Fig. 2A) and increased the endothelial permeability (Fig. 2B), indicating that VEGF-induced vessel leakage might be mediated by ZO-2 protein.

Ang-1 and VEGF have complementary roles during vascular development. VEGF acts early during vessel formation, whereas Ang-1 acts later during vessel remodeling and stabilization (29). Ang-1 is a strong anti-permeability factor that can reduce vascular leakage. When blood-brain barrier breakdown occurs, lesion and perilesional vessels show decreased Ang-1 immunoreactivity (30). Ang-1 suppresses diabetic retinopathy in vivo (31) and coapplication of Ang-1 and VEGF showed a reduction of the brain edema in comparison with VEGF-treated mice (18), supporting the leakage resistant role attributed to Ang-1. However, the regulatory mechanism is still poorly understood. Interestingly, treatment of HBMECs with rAng-1 caused a time- and dose-dependent increase ZO-2 expression and caused a dose-dependent decrease in monolayer permeability by RITC-dextran measurements (Fig. 1). Notably, when we treated both rVEGF and rAng-1 to HBMECs, rVEGF-induced endothelial permeability was significantly reduced and ZO-2 expression was augmented (Fig. 2). Moreover, rVEGF-induced vascular permeability was not recovered by rAng-1 in the group of siRNA targeting ZO-2 (Fig. 3B).

Taken together, we conclude that VEGF enhances endothelial barrier disruption but Ang-1 is able to antagonize this VEGF deleterious effect, in association with an up-regulation of ZO-2. A better understanding of tight junction protein and endothelial barrier regulation by Ang-1 could provide useful therapeutics to treat cerebral vascular disorders such as ischemic brain injury.

\section{Acknowledgements}

We thank the Creative Research Initiatives (NeuroVascular Coordination Research Center) of MOST/KOSEF, Korea for financial support (to K.W. Kim).

\section{References}

1. Staddon JM and Rubin LL: Cell adhesion, cell junctions and the blood-brain barrier. Curr Opin Neurobiol 6: 622-627, 1996.

2. Brightman MW and Reese TS: Junctions between intimately apposed cell membranes in the vertebrate brain. J Cell Biol 40: 648-677, 1969.

3. Abbott NJ: Evidence for bulk flow of brain interstitial fluid. Neurochem Int 45: 545-552, 2004.

4. Lee SW, Kim WJ, Park JA, Choi YK, Kwon YW and Kim KW: Blood-brain barrier interfaces and brain tumors. Arch Pharm Res 29: 265-275, 2006.
5. Gumbiner BM: Breaking through the tight junction barrier. J Cell Biol 123: 1631-1633, 1993.

6. Tsukita S, Furuse $M$ and Itoh M: Multifunctional strands in tight junctions. Nat Rev Mol Cell Biol 2: 285-293, 2001.

7. Fanning AS, Jameson BJ, Jesaitis LA and Anderson JM: The tight junction protein ZO-1 establishes a link between the transmembrane protein occludin and the actin cytoskeleton. J Biol Chem 273: 29745-29753, 1998.

8. Wittchen ES, Haskins J and Stevenson BR: Protein interactions at the tight junction. Actin has multiple binding partners, and ZO-1 forms independent complexes with ZO-2 and ZO-3. J Biol Chem 274: 35179-35185, 1999.

9. Howarth AG and Stevenson BR: Molecular environment of ZO-1 in epithelial and non-epithelial cells. Cell Motil Cytoskelet 31: 323-332, 1995.

10. Stevenson BR, Siliciano JD, Mooseker MS and Goodenough DA: Identification of ZO-1: a high molecular weight polypeptide associated with the tight junction (zonula occludens) in a variety of epithelia. J Cell Biol 103: 755-766, 1986.

11. Beatch M, Jesaitis LA, Gallin WJ, Goodenough DA and Stevenson BR: The tight junction protein ZO-2 contains three PDZ (PSD-95/Discs-Large/ZO-1) domains and an alternatively spliced region. J Biol Chem 271: 25723-25726, 1996.

12. Nag S: The blood-brain barrier and cerebral angiogenesis: lessons from the cold-injury model. Trends Mol Med 8: 38-44, 2002.

13. Goldman CK, Bharara S, Palmer CA, Vitek J, Tsai JC, Weiss HL and Gillespie GY: Brain edema in meningiomas is associated with increased vascular endothelial growth-factor expression. Neurosurgery 40: 1269-1277, 1997.

14. Schoch HJ, Fischer S and Marti HH: Hypoxia-induced VEGF expression causes vascular leakage in the brain. Brain 125: 2549-2557, 2002.

15. Carmeliet P: Angiogenesis in health and disease. Nature Med 9: 653-660, 2003

16. Jain RK: Molecular regulation of vessel maturation. Nature Med 9: 685-693, 2003

17. Yancopoulos GD, Davis S, Gale NW, Rudge JS, Wiegand SJ and Holash J: Vascular-specific growth factors and blood vessel formation. Nature 407: 242-248, 2000.

18. Valable S, Montaner J, Bellail A, Berezowski V, Brillault J, Cecchelli R, Divoux D, Mackenzie ET, Bernaudin M, Roussel S and Petit E: VEGF-induced BBB permeability is associated with an MMP-9 activity increase in cerebral ischemia: both effects decreased by Ang-1. J Cereb Blood Flow Metab 25: 1491-1504, 2005

19. Zhu Y, Shwe Y, Du R, Chen Y, Shen FX, Young WL and Yang GY: Effects of angiopoietin-1 on vascular endothelial growth factor-induced angiogenesis in the mouse brain. Acta Neurochir Suppl 96: 438-443, 2006.

20. Lee SW, Kim WJ, Choi YK, Song HS, Son MJ, Gelman IH, Kim YJ and Kim KW: SSeCKS regulates angiogenesis and tight junction formation in blood-brain barrier. Nature Med 9: 900906, 2003.

21. Choi YK, Kim JH, Kim WJ, Lee HY, Park JA, Lee SW, Yoon DK, Kim HH, Chung $\mathrm{H}$, Yu YS and Kim KW: AKAP12 regulates human blood-retinal barrier formation by downregulation of hypoxia-inducible factor-1alpha. J Neurosci 27: 4472-4481, 2007.

22. András IE, Pu H, Deli MA, Nath A, Hennig B and Toborek M: HIV-1 Tat protein alters tight junction protein expression and distribution in cultured brain endothelial cells. J Neurosci Res 74: 255-265, 2003.

23. Shimojima N, Eckman CB, McKinney M, Sevlever D Yamamoto S, Lin W, Dickson DW and Nguyen JH: Altered expression of zonula occludens-2 precedes increased bloodbrain barrier permeability in a murine model of fulminant hepatic failure. J Invest Surg 21: 101-108, 2008.

24. Petty MA and Wettstein JG: Elements of cerebral microvascular ischemia. Brain Res 36: 23-34, 2001.

25. Fischer S, Wiesnet M, Marti HH, Renz D and Schaper W: Simultaneous activation of several second messengers in hypoxiainduced hyperpermeability of brain derived endothelial cells. J Cell Physiol 198: 359-369, 2004.

26. Dvorak HF, Nagy JA, Feng D, Brown LF and Dvorak AM: Vascular permeability factor/vascular endothelial growth factor and the significance of microvascular hyperpermeability in angiogenesis. Curr Top Microbiol Immunol 237: 97-132, 1999. 
27. Wang W, Dentler WL and Borchardt RT: VEGF increases BMEC monolayer permeability by affecting occludin expression and tight junction assembly. Am J Physiol Heart Circ Physiol 280: H434-H440, 2001.

28. Fischer S, Wobben M, Marti HH, Renz D and Schaper W: Hypoxia-induced hyperpermeability in brain microvessel endothelial cells involves VEGF-mediated changes in the expression of zonula occludens-1. Microvasc Res 63: 70-80, 2002

29. Thurston G, Rudge JS, Ioffe E, Zhou H, Ross L, Croll SD, Glazer N, Holash J, McDonald DM and Yancopoulos GD: Angiopoietin-1 protects the adult vasculature against plasma leakage. Nature Med 6: 460-463, 2000.
30. Thurston G, Suri C, Smith K, McClain J, Sato TN, Yancopoulos GD and McDonald DM: Leakage-resistant blood vessels in mice trans-genically overexpressing angiopoietin-1. Science 286: 2511-2514, 1999.

31. Joussen AM, Poulaki V, Tsujikawa A, Qin W, Qaum T, Xu Q, Moromizato Y, Bursell SE, Wiegand SJ, Rudge J, Ioffe E, Yancopoulos GD and Adamis AP: Suppression of diabetic retinopathy with angiopoietin-1. Am J Pathol 160: 1683-1693, 2002. 